\title{
Wearable Sensors for Human Environmental Exposure in Urban Settings
}

\author{
Carolin Helbig $^{1}$ (D) Maximilian Ueberham ${ }^{2}$ (D) $\cdot$ Anna Maria Becker $^{3}$ (D) $\cdot$ Heike Marquart $^{4}$ (D) $\cdot$ Uwe $^{\text {Schlink }}{ }^{1}$ (D)
}

Accepted: 11 April 2021 / Published online: 7 May 2021

(C) The Author(s) 2021

\begin{abstract}
Global population growth, urbanization, and climate change worsen the immediate environment of many individuals. Elevated concentrations of air pollutants, higher levels of acoustic noise, and more heat days, as well as increasingly complex mixtures of pollutants pose health risks for urban inhabitants. There is a growing awareness of the need to record personal environmental conditions ("the human exposome") and to study options and implications of adaptive and protective behavior of individuals. The vast progress in smart technologies created wearable sensors that record environmental as well as spatio-temporal data while accompanying a person. Wearable sensing has two aspects: firstly, the exposure of an individual is recorded, and secondly, individuals act as explorers of the urban area. A literature review was undertaken using scientific literature databases with the objective to illustrate the state-of-the-art of person-based environmental sensing in urban settings. We give an overview of the study designs, highlight and compare limitations as well as results, and present the results of a keyword analysis. We identify current trends in the field, suggest possible future advancements, and lay out take-home messages for the readers. There is a trend towards studies that involve various environmental parameters and it is becoming increasingly important to identify and quantify the influence of various conditions (e.g., weather, urban structure, travel mode) on people's exposure.
\end{abstract}

Keywords Wearables $\cdot$ Mobile sensors $\cdot$ Participatory sensing $\cdot$ Air pollution $\cdot$ Noise $\cdot$ Thermal stress $\cdot$ Environmental stressors

\section{Introduction}

Wearable sensors are increasingly used to monitor environmental pollution. This development is stimulated by research in four fields of highest relevance: urbanization, climate change, digitalization, as well as innovations in hardware development. Urbanization is leading to an increase in traffic and consequently in noise and air pollution [66]. At the same time, climate change is having a negative impact on urban areas, e.g., resulting in more days of stagnant

This article is part of the Topical Collection on Air Pollution

Uwe Schlink

uwe.schlink@ufz.de

1 Department of Urban and Environmental Sociology, Helmholtz Centre for Environmental Research - UFZ, Leipzig, Germany

2 Centre for Environmental Biotechnology, Helmholtz Centre for Environmental Research - UFZ, Leipzig, Germany

3 Institute of Psychology, Leipzig University, Leipzig, Germany

4 Institute of Transport Research, German Aerospace Centre (DLR), Berlin, Germany urban atmosphere and heat. Therefore, environmental pollution occurs more frequently, longer, and more intensively with citizens suffering from its negative health impacts [94]. In this context, digitalization is a key driver for the development of new ways to collect, assess, and monitor environmental stressors with wearable sensor technologies which help to explore the urban human exposome, which is defined as the total of people's exposure to environmental factors throughout their lifetime [3].

When referring to wearable sensors in this review, we mean small devices that can be easily carried by a person. Some studies used reference or benchmark devices (in laboratories or outdoors), to evaluate the precision of wearable sensors, and some recent reviews and articles about wearable sensor technologies evaluated their technical specifications and performance parameters such as accuracy and precision in different environmental contexts [13, 21, 39, 89, 120]. However, these kinds of evaluation studies are not what we are focusing on in this review. What is missing, to the best of our knowledge, is a comprehensive review of studies that used wearable sensors for different environmental stressors in the urban setting, focusing on personal exposure. With the help of 
this review, we want to answer the following questions: What are current trends in these studies? What are the limitations and gaps in the field? By doing this, we encourage researchers to fill in the blanks and we highlight possible directions for further enquiries. We begin by providing an overview of pollutants in the urban setting, followed by a detailed description of the review process. Next, we present the characteristics of the selected case studies such as study design, equipment and parameters, and limitations as well as a qualitative keyword analysis. In the "Discussion" section, we synthesized the outcomes of the case studies and provide take-home messages for the reader. The paper ends with "Conclusions" pointing out topics that require further research.

\section{Environmental Stressors of Individuals}

Environmental pollution is the sum of all disruptive environmental factors that influence or change the natural environment [71]. Many environmental stressors are harmful to people's health. This review focuses on three environmental factors that are expected to increase in frequency and intensity, especially in urban areas: heat, air pollution, and noise [94]. Urbanization processes mostly densify the built environment, resulting in adverse effects on urban climate and air quality [1]. Environmental exposure of individuals is multi-factorial and three important polluting factors are discussed in the following section $[60,61,109]$.

\section{Airborne Pollutants}

Transport, industry, and agriculture are the main sources of air pollution in cities [93]. The most investigated air pollutants in the context of personal exposure are particulate matter (PM), nitrogen oxides (NOx), carbon dioxide $\left(\mathrm{CO}_{2}\right)$, ozone $\left(\mathrm{O}_{3}\right)$, black carbon (BC), and ultra-fine particles (UFP). Numerous studies show the association between exposure to particulate matter and an increased likelihood of, e.g., cardiovascular or respiratory disease $[65,70,129]$; the other airborne pollutants mentioned in this review are also associated with adverse long-term health effects $[19,55,111,116]$. To limit human exposure to air pollutants, the European Commission provides a legal framework [31], setting average limit values (time reference from hourly to yearly), which have been binding throughout Europe since 2010 [37]. Investigations show that stationary measurements only determine representative concentrations for the location of the measurement and its immediate surrounding [130]. While mobile measurements also represent valid values for a certain radius varying on the microenvironment, stations are not able to determine individual exposure at all [110]. Furthermore, subjective perception of exposure to airborne pollutants has only been examined sporadically in studies so far $[26,48,100]$.

\section{Heat Stress}

Due to their own climatic conditions, cities have higher temperatures than their surrounding areas and urban areas will be affected by heat waves more frequently in the future $[42,49]$. Urban heat island effects impair the performance of healthy inhabitants $[4,47]$ and affect the elderly in particular [28]. For a comprehensive assessment of heat exposure at the level of individuals, subjective heat perception is an important complement to objective exposure [11, 45, 62]. Surveys have shown that, although perceived heat stress is not age-dependent, retired people can better adapt to heat than working people, as they have more flexible daily routines [40]. Temperature observations are mainly gathered by the national weather services. Meanwhile, a denser network of stationary measurements has been established through publicly accessible sensors, which bring together weather stations operated by citizens in all larger cities as an internet-based network. This improves the possibilities to investigate small-scale temperature differences [85].

\section{Noise}

Motor vehicles, rail traffic, air traffic, and industry are the main sources of noise pollution [59]. Noise pollution is a matter of sound frequency and intensity measured in decibels $(\mathrm{dB})$ or $\mathrm{dB}(\mathrm{A})(\mathrm{dB}$ adjusted for the sensitivity of the human ear) and is perceived very subjectively. Adverse health effects include heart disease and sleep and concentration disorders [7, 86, 90, 113, 123]; dementia and diabetes have also been associated with noise [17, 102]. The World Health Organization estimates that in Western Europe, over one million healthy life years are lost annually to noise-related diseases [127]. There is consensus that current guidelines and limit values do not sufficiently promote health-protective urban planning [2, 125, 126]. The EU Environmental Noise Directive does not address individual noise exposure. This gap might be closed by individual worn sensors that record the personal exposure as well as the urban distribution of noise.

\section{From Stationary to Mobile Measurements}

In accordance with guidelines for environmental protection, stationary or model-based concepts still dominate as ways to calculate and estimate urban stressors. However, the ultimate criterion for an individual's health is her/his exposure, which needs to be assessed in more detail. Avoidance of exposure is a way to prevent adverse effects and becomes increasingly important in scientific discourses and socio-political discussions [58]. There are two options for this adaptation. On the one hand, the built environment that influences the extent of environmental stressors can be changed. On the other hand, adaptation can also be behavior-based, e.g., when people consciously decide to change their mobility behavior in everyday life [50], which 
requires awareness, motivation, and knowledge of alternative courses of action [54]. For behavior-oriented adaptation, it is important to be able to evaluate personal exposure. A person's geographical area of action shapes her/his individual exposure and health $[30,57,98,103]$. Recent exposure studies also emphasize the importance of microenvironments along the daily routes of citizens [24, 25, 33, 83].

Personal exposure assessments that follow a mobile approach are still underrepresented in exposure and health research and the geographical context has not yet been studied in depth [22]. Wearable environmental sensors are also a key technology to push the research field of citizen science [38]. Volunteered geographic information (VGI) can be collected by participatory sensing approaches to map personal environmental stressors [76]. VGI is a form of citizen science where laypeople contribute digital data that is used by other citizens but can also serve scientific investigations [27, 44]. Methods in VGI include GPS tracking and geotagging text/picture reports. Subjective experiences and perceptions regarding the environmental situation can thereby supplement measured information to provide a comprehensive understanding of its human health effects.

A vision for the future is to combine mobile sensors with stationary sensors. Budde et al. [15] presented a project in which they developed a network of different sensors. They worked on algorithms for distributed calibration and verification of data sources as well as implemented interfaces between devices, databases, and end-users. In the future, this approach can ensure that large sensor networks can be created in which the different sensors with their respective advantages work together smartly.

\section{Methods}

Due to the rapid development in sensor technology in recent years, we have decided to include publications from the past 5 years in this review. Scientific articles published between January 2015 and February 2020 were searched from the databases Science Direct and ISI Web of Knowledge using the following keywords: wearable/sensor/VGI/pollution/personal exposure/individual exposure/personal sensing/individual sensing/mobile sensing/air/noise/heat. The keywords were used in various combinations. This led to several duplicate results, which were removed in the next step. In addition to the database search, the reference lists of selected and suitable papers were scanned for further case studies. Duplicates and publications that are not journal papers or conference papers were removed from the total of 197 papers (see Fig. 1). The abstracts of these papers were screened to check whether the case studies met the criteria for inclusion in the review. These
Fig. 1 Selection of case studies for the review oriented on the PRISMA flow diagram
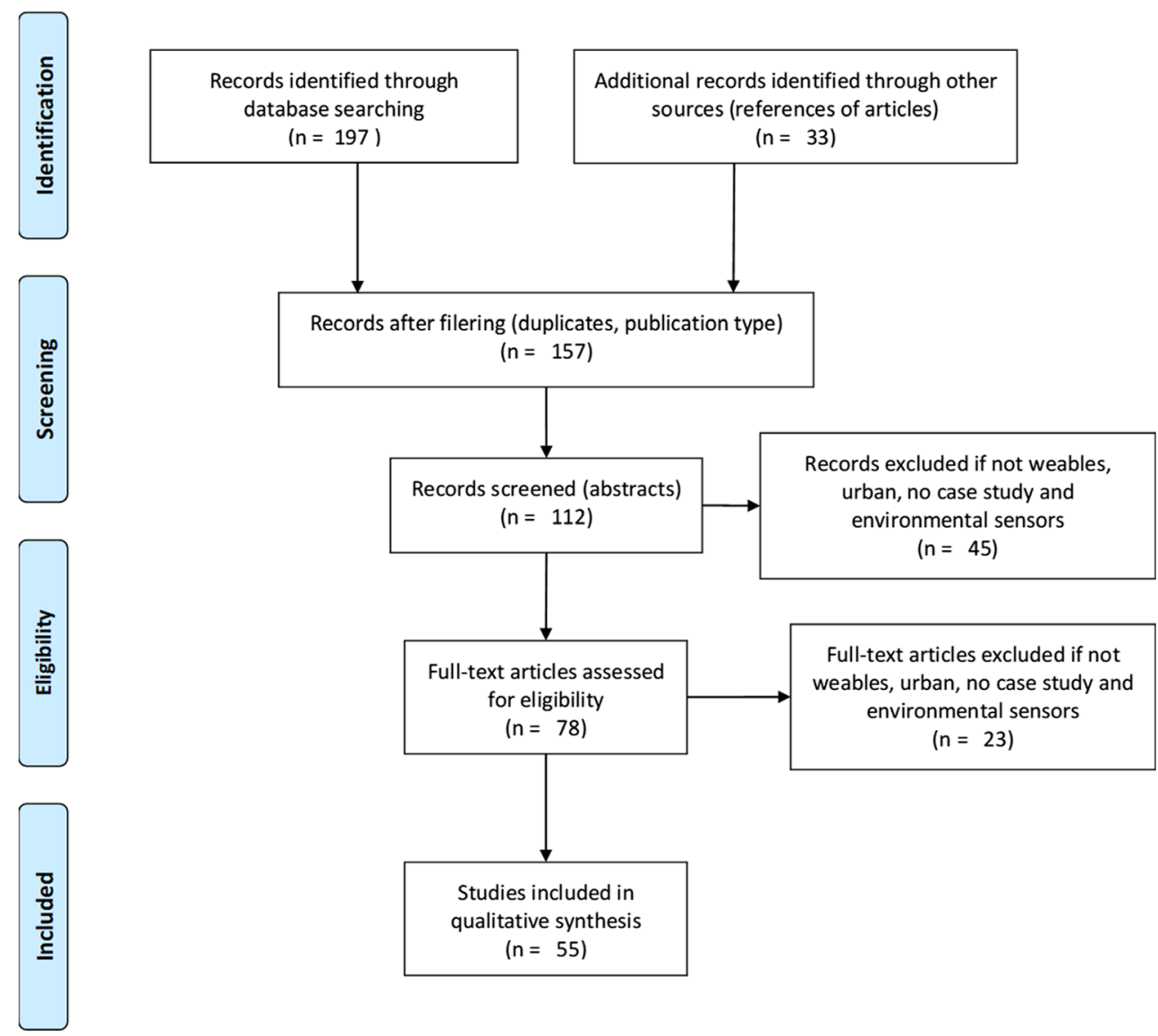
Fig. 2 Database search at Science Direct for "wearable, environment, pollution" publication history of keywords "wearable, environment, pollution" (source: science direct)$$
2000
$$

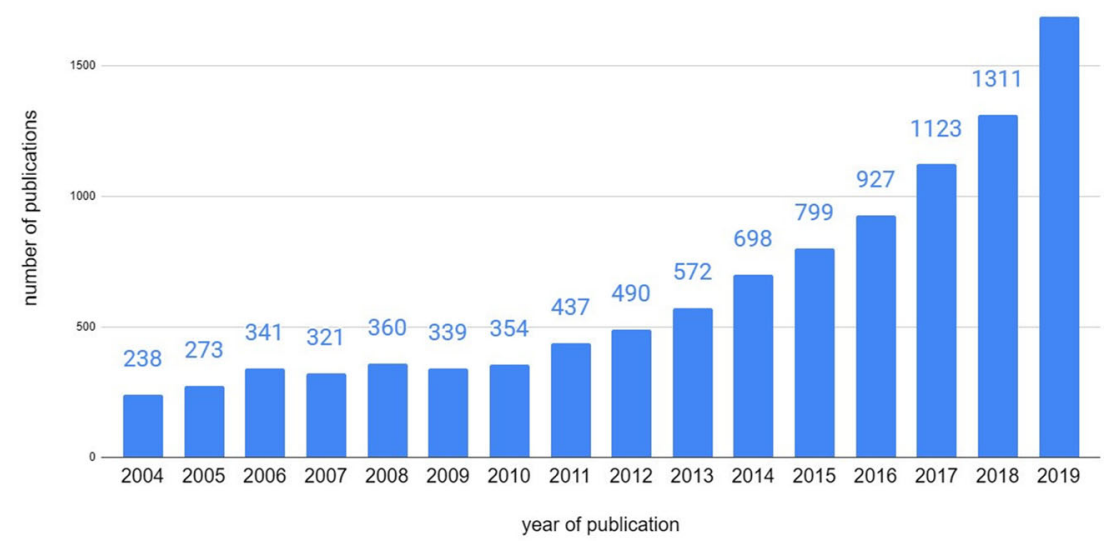

criteria were (i) the use of wearables, (ii) measurement of environmental parameters, and (iii) that the study took place in urban regions (Fig. 2). In a next step, the remaining 78 studies were studied in detail and it was checked again whether the inclusion criteria were met, as in some cases this was not evident from the abstracts.

Parameters of interest were identified from the selected papers, which were captured in a table including the following: authors, year, pollutant, measured parameters, study location, number of participants, data collection period(s), equipment, results, research questions, and study limitations. The studies could then be compared based on these parameters. In addition, a keyword analysis was carried out using the MaxQDA software.

A potential limitation of this review might be that it is possible that not all relevant studies were identified, for example, because they used other keywords/synonyms than those

Fig. 3 Reviewed case studies in terms of environmental pollutant and year of publication which we used in our search. It is also possible that selective reporting within the studies could lead to distortions in the analysis of the results and the limiting factors. Another limitation is that the research was carried out by only one person.

\section{Results}

Figure 2 shows rising numbers of scientific publications focusing on wearable sensors used to monitor environmental pollution in general. Categorizing the selected and reviewed case studies in terms of exposure and year of publication (Fig. 3), we find that initially, wearable sensor applications were mainly used to measure air pollution (12 publications in 2015), but this dominance decayed quickly and soon noise and thermal recordings received similar interest. Most importantly, wearables for thermal exposure are still underrepresented in studies exploring the urban

\section{Number of reviewed case studies}

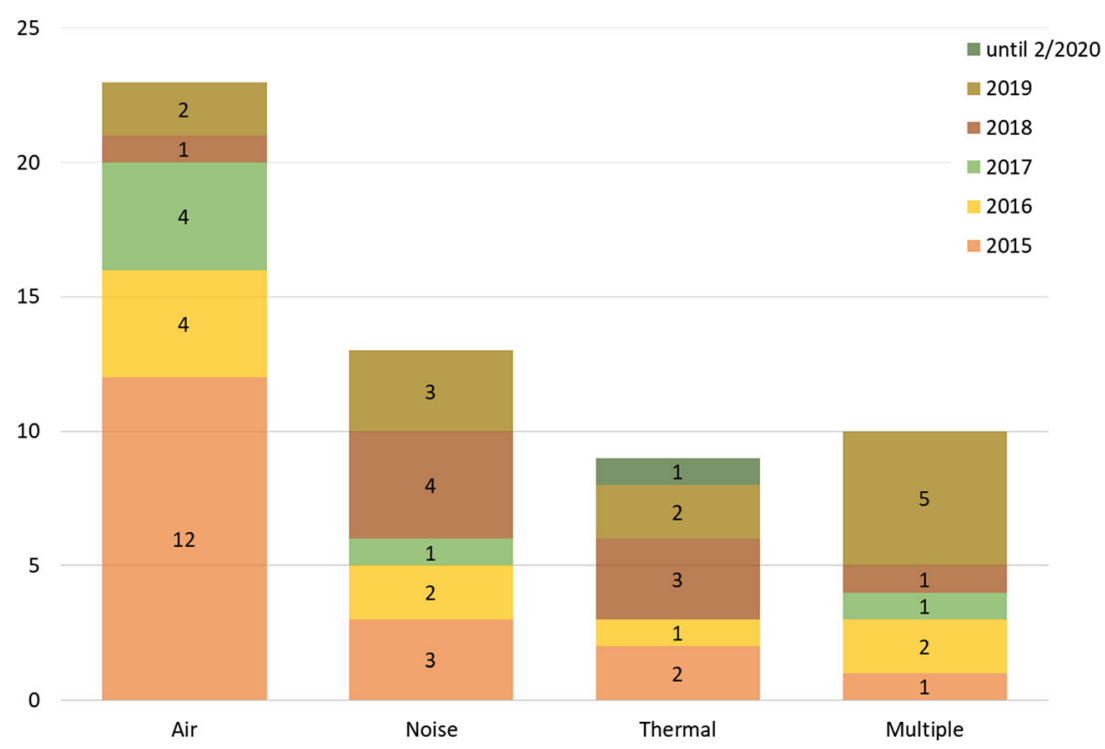


environment. The most recent developments (particularly since 2019) show that multi-parameter wearables are increasingly used, which appears to be an adequate development, given the multi-factorial environmental situation in urban regions.

The analyzed papers can be grouped into the following categories according to their main subject: transport/ commuting mode with regard to spatial and temporal variability (11 articles), microenvironment (indoor/outdoor) pollution ( 8 articles), individual perception/exposure to pollutants ( 8 articles), health-related data in combination with data about pollution (6 articles), sensor and app development and evaluation (14 articles), pollution in multiple locations and local variability (4 articles), and development of pollution maps and basis for simulation ( 5 articles) (detailed information is given in the Appendix).

\section{Study Design}

In the following chapter, the case studies are analyzed and compared using parameters for study design such as location, mode of sensing, number of participants, participant group, duration, sampling period, and time of the year.

The study locations were distributed over five continents (Fig. 4): About half of the European air pollution exposure studies were located in Barcelona (or one of their multiple locations was Barcelona). Two studies had multiple locations in Europe [34, 35]; noise studies were most often conducted in
Paris. The geographical distribution indicates that wearables were mainly used in large metropolises in Europe and North America. Thermal studies are focused on cities in the USA.

When considering the mode of sensing, the case studies can be divided into two groups: (1) 17 studies let the participants carry out the measurements continuously for one or more days and took place indoors (e.g., at home or at work) and outdoors, with the aim of comparing the results $[10,18,23,35,41,51$, $69,77-79,81,87,95,104,108,115,128]$, and (2) 14 studies were limited to the outdoor routes of the participants. Within this group, a further classification can be made according to studies in which the participants (a) travel given routes [20, $32,56,88,114]$ and (b) travel freely chosen routes [34, 43, $72-74,91,96,105,118,121]$ with one or multiple commuting modes (e.g., car, bus, on bicycles, and by foot). While many studies on air and multiple pollutants required participants to use predefined routes, studies on noise exposure collected data from people moving freely through the city and only few focused on predefined streets and places [5, 6]. Measuring indoor noise is of no interest in the selected studies. There are thermal studies which measured both indoor and outdoor $[11,52,62,107,117,119,122]$ and some that only consider outdoor measurements $[8,36]$. The specialty of the temperature parameter is that the outdoor temperature influences the indoor temperature (it should be noted here that this indoor temperature can be influenced by air conditioning systems). This results in exposure to high temperatures not only
Fig. 4 Overview of the geographical regions considered by the 55 reviewed case studies

\begin{tabular}{|c|c|c|c|c|}
\hline & Air & Noise & Thermal & Multiple \\
\hline Europe & $\begin{array}{l}\text { Copenhagen, Denmark (Bekö 2015) } \\
\text { Naples, Italy (Carteni 2015) } \\
\text { Antwerp, Belgium / Barcelona, } \\
\text { Spain / London, UK / Oerebro, } \\
\text { Sweden / Rome, Italy / Vienna, } \\
\text { Austria / Zurich, Austria (Dons 2015) } \\
\text { Antwerp, Belgium / Barcelona, } \\
\text { Spain / London, UK (Dons 2017) } \\
\text { Barcelona, Spain (Jerrett 2017) } \\
\text { Belgium (Louwies 2015) } \\
\text { Lisbon, Portugal (Do Vale 2015) } \\
\text { Barcelona, Spain (Nieuwenhuijsen } \\
\text { 2015) } \\
\text { Barcelona, Spain (Rivas 2016) } \\
\text { London, UK (Rivas 2017) } \\
\text { Como, Italy (Spinazzè 2015) } \\
\text { Scotland, UK (Steinle 2015) }\end{array}$ & $\begin{array}{l}\text { Spain (Aspuru 2016) } \\
\text { Italy (Longo 2017) } \\
\text { Griechenland (Bakogiannis 2018) } \\
\text { Paris, France (Aumond 2018, De } \\
\text { Coensel 2015, Lefevre 2019, Ventura } \\
\text { 2018) } \\
\text { France / Belgium / Finland (Lefevre } \\
\text { 2018) }\end{array}$ & & $\begin{array}{l}\text { United Kingdom (Chatzidiakou 2019) } \\
\text { United Kingdom (Moore 2016) } \\
\text { Germany (Ueberham 2019) } \\
\text { Finland / Neatherlands / Greece } \\
\text { (Okokon 2017) }\end{array}$ \\
\hline $\begin{array}{l}\text { North } \\
\text { America }\end{array}$ & $\begin{array}{l}\text { Lubbock, Texas, USA (Cao 2016) } \\
\text { USA (Gaskins 2019) } \\
\text { Houston, Texas, USA (Lu 2014) } \\
\text { Cincinnati, Ohio, USA (Ryan 2015) }\end{array}$ & USA (Picaut 2019) & $\begin{array}{l}\text { Boone, North Carolina / Starkville, } \\
\text { Mississippi (Bailey 2020) } \\
\text { Boone, North Carolina / Raleigh, } \\
\text { North Carolina / Starkville, } \\
\text { Mississippi (Runkle 2019) } \\
\text { Boone, North Carolina / Raleigh, } \\
\text { North Carolina / Starkville, } \\
\text { Mississippi (Sugg 2018) } \\
\text { Boone, North Carolina / Raleigh, } \\
\text { North Carolina / Starkville, } \\
\text { Mississippi (Thompson 2018) } \\
\text { Birmingham, Alabama (Bernhard } \\
\text { 2015) } \\
\text { Tallahassee, Florida (Dumas 2016) } \\
\text { Tallahassee, Florida (Uejio 2018) } \\
\text { Knoxville, Tennessee (Hass 2019) } \\
\text { Boston, Massachusetts (Kuras 2015) }\end{array}$ & $\begin{array}{l}\text { USA (Good 2016) } \\
\text { USA (Mallires 2019) } \\
\text { USA (McKercher 2018) }\end{array}$ \\
\hline $\begin{array}{l}\text { South } \\
\text { America }\end{array}$ & $\begin{array}{l}\text { Londrina, Brazil (Targino) } \\
\text { Bogota, Colombia (Morales } \\
\text { Betancourt 2017) }\end{array}$ & & & \\
\hline Asia & $\begin{array}{l}\text { Shanghai, China (Lei 2016) } \\
\text { Shanghai, China (Li 2015) } \\
\text { Beijing, China (Ma 2019) }\end{array}$ & Hongkong, China (Hu 2015) & & $\begin{array}{l}\text { China (Chatzidiakou 2019) } \\
\text { China (Han 2020) } \\
\text { Taiwan (Liu 2015) } \\
\text { India (Nagendra 2019) }\end{array}$ \\
\hline Oceania & $\begin{array}{l}\text { Auckland, New Zealand (Lim 2015) } \\
\text { Brisbane, Australia (Williams 2016) }\end{array}$ & Australia (Rana 2015) & & \\
\hline
\end{tabular}


outdoors but also indoors, especially at night. Practices to adapt to extreme heat are the focus of several studies (e.g., $[107,119,122])$, which requires both the indoor and outdoor temperatures to be recorded.

The number of participants in the analyzed studies varied over a wide range. In eight of the air pollution studies, the participants using the wearable sensors were scientists who most likely work within the project $[20,32,73,78,105$, $114,118,128]$. Their focus was on the feasibility of data collection and device evaluation and not on the measurement of a person's personal exposure. Three heat studies recruited ground management workers as they are particularly exposed during outside work $[11,107,117]$. The number of participants in heat studies varied between 23 [62] and 81 [11]. The other studies involved participants in a range between 4 and 300 (Fig. 5), except Picaut et al. [99], who used a smartphone app and report that more than 24,000 participants contributed to around 85,500 measurement paths [99]. Studies of air pollutants and multiple exposures involved mostly volunteers and it appears that more recent studies recruited a larger number of participants than previous studies.

The case studies focused on different participant groups, thereby examining different aspects of exposure. Four of the air pollution studies recruited participants from former healthrelated studies [34, 41, 56, 95]. Also recruiting participants with pre-existing health issues, Ryan et al. [108] studied 20 children with asthma. Bekö et al. [10] and Dons et al. [35] underline that their participants were in good health. Some studies were conducted with school children [95, 104, 108] or graduate students [69]. Some studies focused on occupational groups: Louwies et al. [77] recruited nurses and three studies involved ground workers [11, 107, 117].
The duration of the case studies varied between 2 and 40 days; some studies were focused on a particular time of the day, e.g., peak-hours $[20,105,114]$ for air pollution exposure, or comparing rush hours and off-peak times $[6,53,101]$ in noise studies. In most of the heat studies, a sampling period of 5 days, or the so-called work week, was applied [8, 11, 107, $117,119]$. Obviously, heat exposure is most relevant during the summer months and this is reflected in the seasonal pattern of thermal studies (Fig. 6). Measurements of air pollution and multiple exposure studies are spread throughout different times of the year. Noise studies are not uniformly distributed over all seasons, which might be a random pattern due to the low number of studies.

\section{Parameter and Equipment}

In the following chapter, different parameters measured in the case studies are categorized and described. In addition, we give an overview of the utilized sensor equipment.

Figure 7 shows that measurements of gaseous pollutants (NOx, COx, O3) are quite scarce in air pollution studies, while particulate matter was frequently recorded and measured in many different forms (mass concentration PM, particle number concentration PNC, black carbon $\mathrm{BC}$, ultra-fine particulates UFP, total suspended particles TSP). Seven studies utilized a questionnaire or diary (e.g., demographic data, activity logs). Some studies, such as Lefevre and Issarny [67] and Lefevre et al. [68], applied different stages of participation each with a different number of participants: participants who measured with a smartphone app, filled out questionnaires, and participated in workshops. Eight studies additionally collected data about the participants' health (medical data; it should be noted that

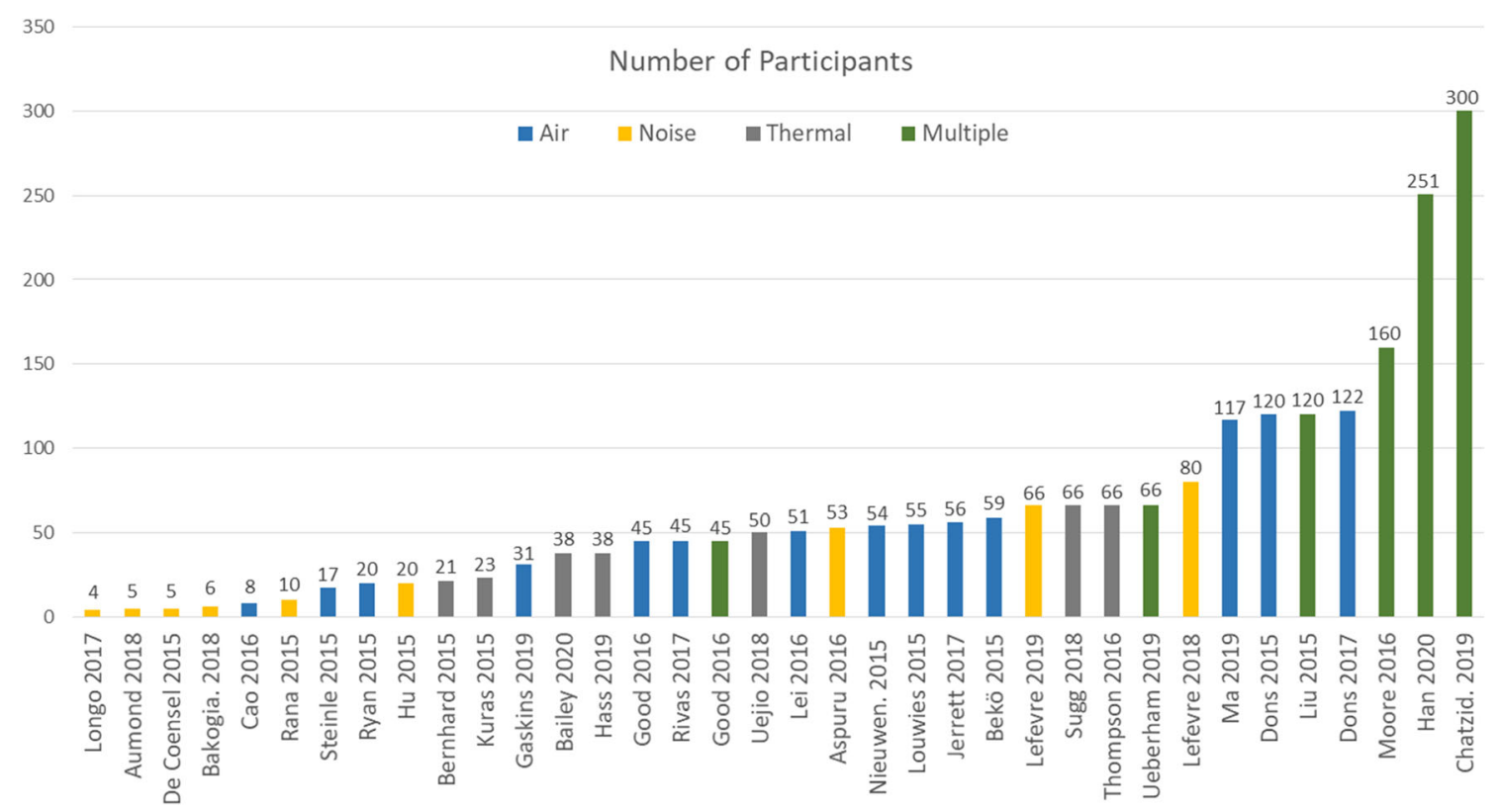

Fig. 5 Overview of sample sizes in the case studies 
Fig. 6 Seasonal distribution of measurement periods

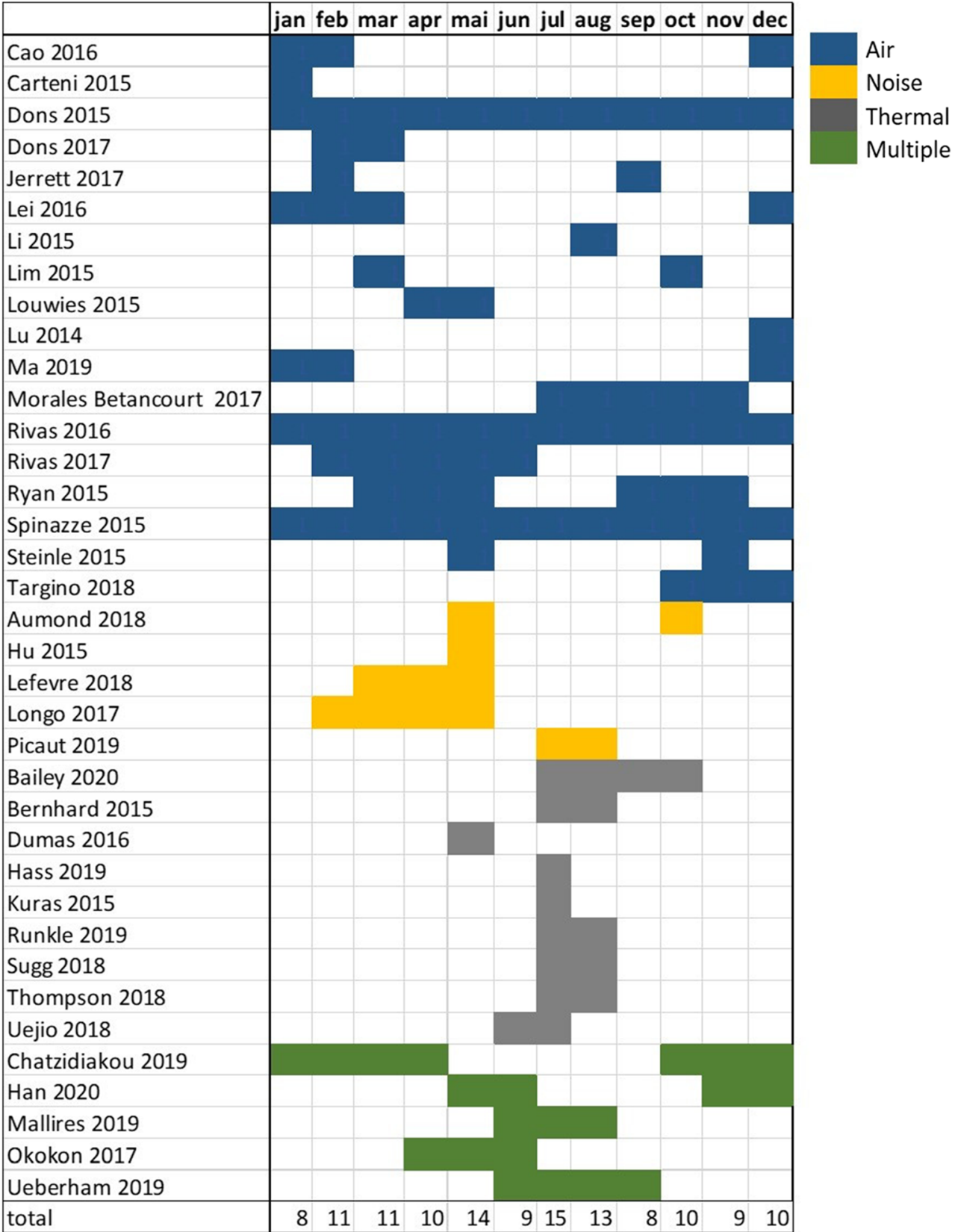

this review is not focused on discussing the results that emerge from the evaluation of the medical data). Figure 7 also reveals an important weakness of the thermal case studies performed with wearables: most studies only measured temperature, but did not capture other important contributions to thermal comfort, such as radiation, air humidity, and wind speed. This is certainly due to the technical difficulties of measuring the additional components and, so far, only some initial attempts have been made to develop devices that conveniently register these components (e.g., Nakayoshi et al. [92]).

In contrast to air, noise, and multiple exposure studies, only a minority of the thermal case studies collected GPS data of their participants as well as data about the participants' movement (location, acceleration, questionnaires). Some studies set their focus on investigating the thermal effects on individuals and did not capture GPS data since the focus is not on the spatial characteristics of the parameter. Others did not involve GPS, as data about personal mobility are confidential [52]. Runkle et al. [107] as well as Sugg et al. [117] identified a subset of their participants who were willing to use GPS trackers and utilized geo-locations in combination with selfreported activity logs. GPS records were synchronized with the recordings of the environmental sensors by using a timestamp. The positions of the recordings can be assigned to land cover categories [117] or utilized to create population density surfaces and maps [119]. 


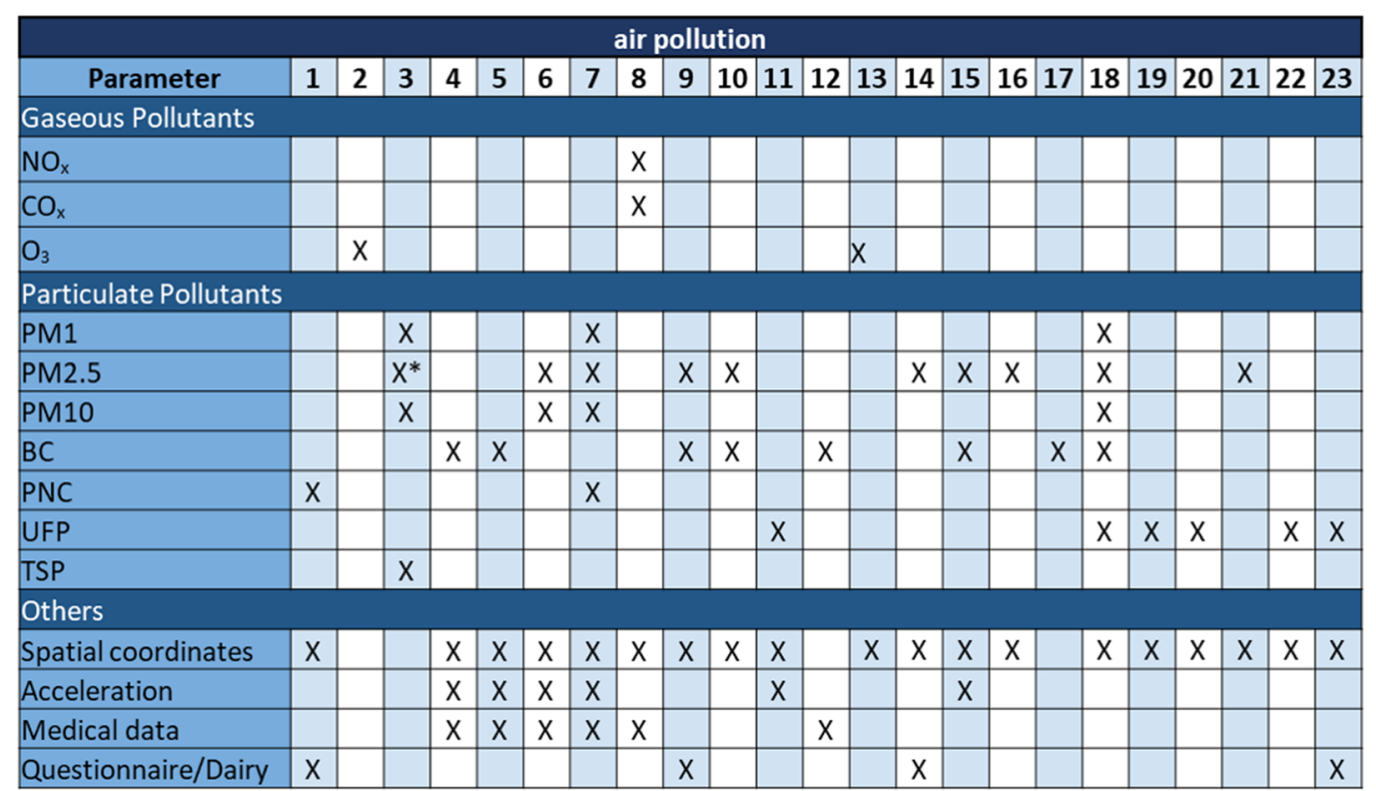

1: Bekö 2015, 2: Cao 2016, 3: Carteni 2015, 4: Dons 2015, 5: Dons 2017, 6: Do Vale 2015, 7: Ganskins 2019, 8: Jerrett 2017, 9: Lei 2016, 10: Li 2015, 11: Lim 2015, 12: Louwies 2015, 13: Lu 2014, 14: Ma 2019, 15:

Morales Betancourt 2017, 16: Nieuwenhuijsen 2015, 17: Rivas 2016, 18: Rivas 2017, 19: Ryan 2015, 20 :

Spinazze 2015, 21: Steinle 2015, 22: Targino 2018, 23: Williams 2016

$*+$ PM7

\begin{tabular}{|c|c|c|c|c|c|c|c|c|c|}
\hline \multicolumn{10}{|c|}{ thermal pollution } \\
\hline Parameter & 1 & 2 & 3 & 4 & 5 & 6 & 7 & 8 & 9 \\
\hline \multicolumn{10}{|l|}{ Meteorological Parameters } \\
\hline Temperature & $x$ & $x$ & $x$ & $x$ & $\mathrm{x}$ & $x$ & $x$ & $x$ & $x$ \\
\hline Experienced temperature & & & & $\mathrm{x}$ & $\mathrm{x}$ & & & & \\
\hline Relative humidity & & & & $x$ & & & & & \\
\hline \multicolumn{10}{|l|}{ Others } \\
\hline Location & & $\mathrm{x}$ & & & & & & & \\
\hline Light intensity & & $x$ & & & & & & & \\
\hline
\end{tabular}

1: Bailey 2020, 2: Bernhard 2015, 3: Dumas 2016, 4: Hass 2019, 5: Kuras 2015, 6: Runkle 2019, 7: Sugg 2018, 8:

Thompson 2018, 9: Uejio 2018
Fig. 7 Overview of measured parameters in the case studies

In some studies, participants reported their location: indoor (home, work, visiting a friend/relative, church, store, and other), outdoor (work, recreation, visiting a

\begin{tabular}{|c|c|c|c|c|c|c|c|c|c|c|}
\hline \multicolumn{11}{|c|}{ multiple exposure } \\
\hline Parameter & 1 & 2 & 3 & 4 & 5 & 6 & 7 & 8 & 9 & 10 \\
\hline \multicolumn{11}{|l|}{ Gaseous Pollutants } \\
\hline $\mathrm{NO}_{\mathrm{x}}$ & $\mathrm{x}$ & & $x$ & & & $\mathrm{X}$ & $\mathrm{X}$ & $\mathrm{x}$ & & \\
\hline $\mathrm{CO}_{\mathrm{x}}$ & $x$ & $\mathrm{x}$ & $x$ & & & $\mathrm{x}$ & $x$ & $x$ & & \\
\hline $\mathrm{O}_{3}$ & $x$ & & $x$ & & $\mathrm{X}$ & & $x$ & $\mathrm{x}$ & & \\
\hline VOCs & & & & $\mathrm{X}$ & $\mathrm{X}$ & & & & & \\
\hline \multicolumn{11}{|l|}{ Particulate Pollutants } \\
\hline PM1 & $x$ & & $\mathrm{x}$ & & & & $\mathrm{X}$ & & & \\
\hline PM2.5 & $\mathrm{x}$ & $\mathrm{X}$ & $x$ & $\mathrm{X}$ & & & $\mathrm{X}$ & $\mathrm{x}$ & $x$ & \\
\hline PM10 & $\mathrm{x}$ & & $x$ & $\mathrm{x}$ & & & $x$ & & $x$ & \\
\hline $\mathrm{BC}$ & & $\mathrm{x}$ & $x$ & & & & & & $x$ & \\
\hline PNC & & $\mathrm{x}$ & & & & & & & $x$ & $x$ \\
\hline \multicolumn{11}{|c|}{ Meteorological Parameters } \\
\hline Temperature & $x$ & $\mathrm{X}$ & $x$ & $\mathrm{X}$ & $\mathrm{x}$ & $\mathrm{X}$ & $\mathrm{X}$ & $x$ & & $\mathrm{x}$ \\
\hline Relative humidity & $x$ & $\mathrm{X}$ & $x$ & $x$ & $\mathrm{x}$ & $x$ & $\mathrm{X}$ & $\mathrm{X}$ & & $x$ \\
\hline Barometric pressure & & & $x$ & & & & & & & \\
\hline $\begin{array}{l}\text { wind (speed, } \\
\text { direction) }\end{array}$ & & & $x$ & & & & & & & \\
\hline \multicolumn{11}{|l|}{ Others } \\
\hline Spatial coordinates & $x$ & $\mathrm{X}$ & $x$ & & & $\mathrm{X}$ & $\mathrm{X}$ & $\mathrm{x}$ & $x$ & $\mathrm{X}$ \\
\hline Acceleration & $x$ & $\mathrm{x}$ & $x$ & & $x$ & & $x$ & & & \\
\hline Noise & $x$ & & $x$ & $x$ & & $x$ & $\mathrm{x}$ & & $X$ & $\mathrm{x}$ \\
\hline Light intensity & & $\mathrm{x}$ & & & & $x$ & & & & \\
\hline Medical data & & & $x$ & $x$ & & & & & & \\
\hline Questionnaire/Dairy & & & $x$ & & & & $x$ & & & $x$ \\
\hline \multicolumn{11}{|c|}{$\begin{array}{l}\text { 1: Chatzidiakou 2019, 2: Good 2016, 3: Han 2020, 4: Liu } \\
\text { 2015, 5: Mallires 2019, 6: McKercher 2018, 7: Moore } \\
\text { 2016, 8: Nagendra 2019, 9: Okokon 2017, 10: } \\
\text { Ueberham } 2019\end{array}$} \\
\hline
\end{tabular}

friend/relative, activities, and shop), and in-transit (vehicle, walking and work), as well as their activities while sensing $[107,117,119]$, e.g., by degree of activity (heavy 
(jogging), moderate (walking), resting (no activity); [36]). Hass and Ellis [52] also inquired for activities that may influence experienced temperatures (e.g., use of air conditioners, minimizing outdoor work, drinking fluids, wearing light clothing, wearing a hat, reducing activities, seeking shade). Hass and Ellis [52] as well as Kuras et al. [62] registered the experienced temperature of the participants by selecting their thermal comfort from several possible categories (cold, neither hot nor cold, warm, hot, very hot).

Some studies also acquired demographics and socioeconomic data to analyze associations with environmental data [11]. Sugg et al. [117] and Kuras et al. [62] asked their participants for information about, e.g., age, race, gender, housing status, activities during the week, lifestyle, occupation, orientation towards the neighborhood, use of indoor and outdoor spaces, and public and private cooling resources. In studies aimed at exploring health effects, participants' height, weight, and body composition were registered together with health symptoms $[117,119]$.

Considering the utilized equipment, we find that microaethalometers are frequently used ( 9 studies, see Fig. 8 in the Appendix). For noise measurements, smartphones were utilized almost exclusively. The volume of noise was registered as $\mathrm{dB}$ or $\mathrm{dB}(\mathrm{A})$ and some authors recorded the $1 / 3$ octave band spectrum $[6,29]$. Current smartphones contain embedded microphones capturing sound pressure levels from 30 to at least $120 \mathrm{~dB}[5,46]$ or attach an external microphone to the smartphone to measure noise levels. Examples of noise-measuring smartphone applications are as follows: Sound Meter [9], ISEISense [53], Ambiciti [67, 68], CitySoundscape [75], iNoiseMapping [82], NoiseCapture [99], Ear-Phone [101], and others [5, 124]. Lefevre and Issarny [67] and Lefevre et al. [68] reported that their app uses a calibration technique, as the embedded microphones of the smartphones can be very heterogeneous. Aspuru et al. [5] argued that older participants experienced the sensor techniques as rather complex and not very intuitive, while younger participants considered it practical, user-friendly, manageable, and intuitive. For multiple exposure measurements, many authors developed their own personal monitoring systems, often by composing sets of multiple devices (see Fig. 8 in the Appendix for references and details given therein).

In temperature-measuring studies, most thermal sensors did not have any ventilation unit and sun protection shield, which might have resulted in unreliable measurements of air temperature. An exception was Bailey et al. [8] who utilized a "fire weather monitor" measuring temperature, relative humidity, heat stress index, dew point, wet bulb temperature, and air pressure. Hass and Ellis [52] and Liu et al. [74] additionally registered humidity data and Bernhard et al. [11] measured the light intensity.

\section{Limitations Faced by the Case Studies}

Several studies limited the variety of their sensors due to cost and usability issues (e.g., Nieuwenhuijsen et al. [95] decided to measure only black carbon as it is a marker for trafficrelated air pollution). However, most authors realized the need of additional parameters, such as the inhalation rate [118], which was not directly measured, but estimated [78]. Data about traffic fluxes [114] and the details of travel modes [10] and air exchange rates in the different means of transport [72] are also lacking in most studies. Several studies mention the number of participants $[18,95]$ and the number of days $[10$, $72,78,114]$ as limiting factors, especially for studies with children who are limited in their participation capacities [95]. Lefevre et al. [68] emphasized that a critical mass of participants as well as a greater involvement of policymakers in the case studies would lead to more relevant representations of the urban noise environment.

Limitations caused by the sensors refer to battery life [18], the noise of the sensors [108], their weight [41, 108], and wearing comfort [78] which limited the time, for which participants could be asked to wear them [9]. Some sensors required a specific data analysis setup, which was tailored to a specific location [6]. In one study, the sensors produced lots of detailed data, so that internal storage reached its limits [41]. Often the technical solutions combining sensors and smartphones are limited to a specific smartphone model [5]. Furthermore, the sensors' precision and reaction time influence data accuracy. Some authors report on sensors, which cannot detect variation of parameters below a given level [78] and on limitations in response time, leading to inaccuracies in the quantitative description of very rapid personal exposure events $[18,19]$.

Studies of heat exposure might suffer from incorrect logs, e.g., participants marked "outside," but have been inside a restaurant [11] or drove air-conditioned vehicles [117], or $\log$ information was incomplete in general [52]. This could also be the case for volunteers' recordings of personal appraisals, their habits, and whether they were wearing the sensors correctly [8]. More accurate indoor/outdoor activity patterns might be inferred from solar radiation monitors [122].

Limitations of the study results are often caused by the study time and location. While in recordings of short duration the sample size might be insufficient (only one week of data deny observations of the effect of the day of week [62]), long-term studies might be biased by the volunteers' perceptions and their adaptive change of behavior during the study [121]. Some bicyclists sought routes further away from busy traffic streets and this might reduce exposure by about $30 \%$ on average [96]. Hass and Ellis [52] reported an unintended influence by the researchers, as they made participants aware that they were investigating the differences in exposure and actions and behaviors between heat wave 
and normal conditions which may have influenced the participants' reported adaptive actions.

The lack of data on further exposure factors not measured in a study (e.g., carbon monoxide, nitrogen dioxide) can confound the observed associations between measured data of PM, TVOCs, and heart rate variability [74]. Kuras et al. [62] argue that for an improvement of the results, it would have been necessary to integrate additional data, e.g., socioeconomic data on the scale of city, the neighborhood, and household as well as biophysical data.

Data quality was often more difficult to guarantee as the number of the participants and the amount of data collected were increasing. To improve quality, post-processing methods can be implemented [99]. GPS accuracy can be low which can annihilate the reliability of the measurement. The orientation of sensors and the location they were attached to (e.g., on top of each shoe, hanging on lanyard under front of shirt) have also had an influence on the results of measurements $[36,106$, 107, 122].

For thermal sensors, the influence of direct sunlight/radiant heat was reported as an important factor in several studies [11, $52,62,63,117]$. Errors in humidity measurements occurred, if sensors detected sweat through clothing or participants remained near air conditioning vents [52]. Bernhard et al. [11] and Bailey et al. [8] observed differences between records of wearables and the data registered by fixed weather stations, occurring due to different sampling frequency and spatial distance. In some cases, weather conditions had a strong influence on the results; e.g., cloud cover may have reduced heat waves and their influence on participants [52]. Extreme environmental conditions, such as temperatures higher $40^{\circ} \mathrm{C}$, disrupted the performance of the $\mathrm{CO}, \mathrm{NO}$, and $\mathrm{NO} 2$ sensors [23]. Okokon et al. [96] discussed the influence of wind and rain events on measurements, especially while cycling. Data accuracy can be improved by merging data of different sources $[11,117]$. This is necessary, particularly with lowcost sensors [84].

\section{Results of the Case Studies}

Exposure in different environments was compared by several authors. In the studies, in which measurements were taken over a period of one or more days, it was found that the participants spend a large part of the time indoors. Nevertheless, the highest pollutant concentration was not measured at home [18], but in passive transportation [10, 69] and/or during commuting [10, 69, 72, 95, 104, 108]. Interestingly, several authors $[73,88,118]$ observed that pollutant concentrations had higher variations within single routes, as compared to the variability during a given day. They identified peaks of high concentrations, especially in UFP concentrations, when travelling at low speeds and when a bus stopped close to traffic light intersections. Spinazzè et al.
[114] described the influence of the monitoring period on exposure and reported the highest measured exposures for walking or cycling along high-trafficked routes and while using public buses. Do Vale et al. [32] further pointed out the influence of the slope of a street on the inhalation rate.

Sociodemographic characteristics of the volunteers are often associated with their exposure (for heat exposure, see [11, $52,62,106])$. Correlations between personal exposure and health have been analyzed and associations were found between blood pressure and subchronic black carbon exposure in healthy adults, which suggests that black carbon exposure can lead to cardiovascular health effects [77]. Dons et al. [34] conducted their air pollution exposure study under real-life conditions with 120 participants, combining qualitative and quantitative methods. The authors evaluated existing methods to estimate inhaled dose and highlighted the differences between these methods [35], based on their large and unique data set collected in three cities, over three seasons, covering a range of personal factors, meteorological conditions, and local conditions [35].

From the data gathered by personal sensors, several authors developed pollution, noise, and heat maps $[6,82]$ and combined these data with the information of fixed monitoring stations $[29,101]$ or with the participants' subjective observations $[5,99]$. Lu and Fang [78] present their results of measuring personal exposure of a participant using $3 D$ visualization and constructed personal air pollution and health risk maps based on an individual's 2-day ozone exposure, intake, and danger zones in Houston, TX. A comparison with fixed stations was conducted by Rivas et al. [104], who showed that personal BC concentrations were $20 \%$ higher than in fixed stations at schools. Similarly, Ma et al. [79] found that exposure estimates generated by monitoring station assessment versus real-time sensing assessment varied substantially. In combination with other factors, this could generate considerable differences in the estimation of personal pollution exposure. Steinle et al. [115] emphasize the need for personal exposure measurements to get reliable data about the real individual exposure.

Lefevre et al. [68], as well as Ventura et al. [124], promoted mobile phone sensing as a promising complement to the stateof-the-art approaches to urban monitoring, resulting in high spatial resolution maps related to urban environmental conditions and human activity. Crowd-sensing allows new forms of citizens' participation in urban contexts which enables them to take part in political processes: gathering data and raising awareness for urban exposure could improve citizens' quality of life and may support decision-makers in urban planning procedures [75].

Some studies report about sensor development and evaluations. Cao and Thompson [18] developed a portable, easy to use, sensitive, and low-cost ozone sensor. Gaskins, Hart [41] presented their AirBeam2 personal monitor, which 
is low cost, able to collect multiple size fractions of PM data every second, portable, and able to track GPS location, and allows participants to observe their real-time exposure information. They compared it with the emmET, which has a high level of accuracy, collects data for a long period of time without burdening the participant, but is restricted by only measuring the indoor home environment as it is not portable. Personal sensor measurements have also been compared to those from more expensive instruments. It turned out that personal sensors are more closely correlated with expensive research instruments than with the government monitors [56].

\section{Keyword Analysis}

The work on this review revealed a high diversity of topics that have been related to human exposure. Therefore, it is helpful to identify what the hot topics are and where there are still research gaps. Therefore, a descriptive analysis of keywords (all words in the articles) was performed. All 55 papers were scanned using the software MAXQDA Analytics Pro (v2020, word counts, and code maps). All words were counted and listed by frequency (see list in attachment). Additionally, clusters of words with close occurrence in the articles were generated. Four clusters appear in the cluster map (see the Appendix). One large cluster around the keywords "personal," "health," and "pollution" reveals that they are often related to mobility (walking, cycling, traffic, activity, behavior) or locations (spatial, home, school). The more interesting results are the three single word clusters of "weather," "microenvironment," and "commuting." These keywords seem to be only rarely used together with the first cluster. It is shown that "microenvironment" is not closely related to school, home, walking, or cycling as these terms might represent specific microenvironments. Probably the keyword has been used for different types of microenvironments; however, there is no consistent use, indicating further research needs. We also conclude that aspects of weather in relation to personal exposure require more attention in further research. Many studies performed their sensor tests or measurements under optimal weather conditions. Weather is of high relevance for measuring exposure values but can also influence human behavior to a large extent [14].

\section{Discussion}

After reviewing the case studies based on their characteristics of study design, parameters, and equipment, as well as the limitations and results of the studies, we will interpret these results in this chapter and at the end formulate short take-home messages for the readers. We refer to the questions formulated in the "Introduction" section on which direction the studies are developing and what sort of limitations and gaps appeared, allowing us to show up directions for further enquiries in the field.

Studies on personal exposure to urban stressors can help to realistically assess and avoid misclassification of individual exposure loads in the future [63]. Due to the current technical developments and the fact that a large number of people own smartphones, it is feasible to use wearables to measure environmental parameters, as they are relatively cheap and many people already own personal devices. As this review showed, in case studies in the field of noise pollution, smartphones are already the most frequently used device in combination with an app. The trend towards increasing precision and decreasing prices of wearables will probably allow researchers to involve even more participants in the studies of air pollution and heat stress in the future and thereby gain more data and achieve greater reliability and generalizability of the research results. However, authors of future studies have to trade strengths for limitations (see Table 1) of wearables depending on their study design.

The number of multi-case studies increased within the last years. In addition, a number of studies stated the need to integrate additional parameters. One challenge to tackle now is to develop sensors for the simultaneous measurement of multiple parameters. Most case studies of the review have taken up this challenge and focused on sensor and app development and evaluation. One difficulty here is to consider aspects of wearing comfort, as sensors must be pleasant for the participants, especially if one strives for
Table 1 Strengths and limitations of the use of wearables

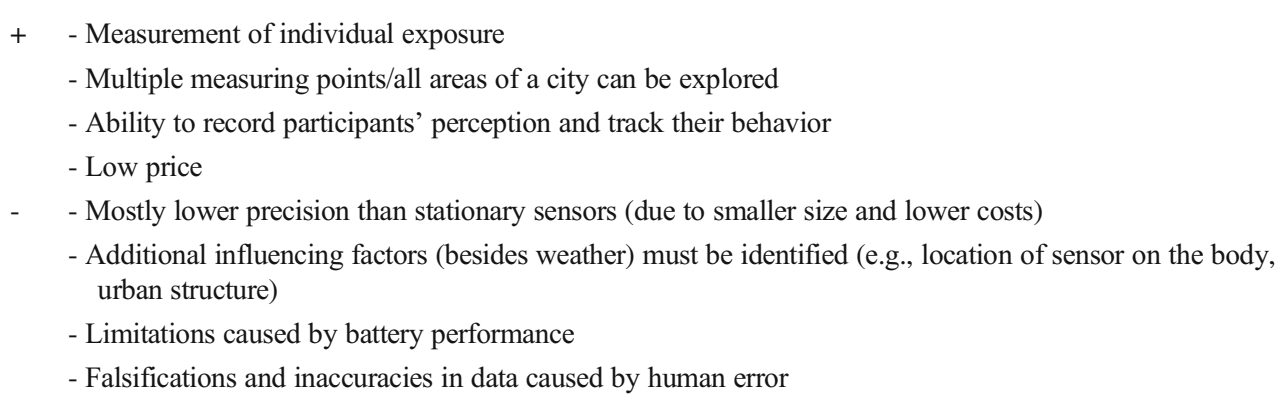


longer measuring times. However, the size of the sensors is often directly related to their accuracy and battery life. It has to be weighed carefully between the desired measurement accuracy [99], budget, and wearing comfort. Another difficulty is to develop sensors with respect to usability and human-computer interaction (HCI) aspects, which play an important role in participants' acceptance [16]. This aspect still plays a subordinate role in the presented case studies and should be given more attention in future studies. Another approach that appears in this context and should be taken into account in the future is the inclusion of artificial intelligence. For example, in some situations, the sensors could decide for themselves whether a measurement should be carried out in a specific situation or not [101]. Taking these aspects into account would probably also minimize the occurrence of human error, which was stated as a limitation in many of the studies [8], and thus lead to more analyzable data.

The studies focusing on transport, commuting modes, and microenvironments show a variety of conditions influencing the measured data, such as ventilation, street geometry, traffic situation on the street (e.g., stopping at traffic lights), duration of stops, travel direction (uphill/ downhill), weather conditions, and many more. Future studies should aim to identify these conditions and quantify their impact. Especially when creating maps and simulations, these influences must be integrated. For instance, the influence of weather conditions on measurement results is not well investigated. This also leaves the open question, whether the sensors are suitable for extreme environmental conditions such as extreme heat or extreme air pollution. Taking a look at the case study regions in this review, most research on environmental pollutants in urban environments has been done in Europe (especially air and noise pollution). It would be interesting to see more studies conducted in areas with higher exposure to environmental pollutants, such as in Asia and Africa. For example, comparative studies could be aimed at two locations, in which knowhow and equipment are shared through cooperation.

Three types of measurements can be identified: mobile, stationary and subjective perception of exposure. It would be interesting to see studies showing these combined. Options (e.g., 3D visualization) to analyze and combine the multiple parameters have also be developed.

Some studies in this review stated that most people spend the majority of time indoors and not outdoors or moving. Certainly, it should be emphasized that the high peak exposures of individuals occur outdoors, and these events seem to be most relevant for negative health effects in the long term. There is however only little evidence for this hypothesis and more studies should investigate the ratio of time and intensity of environmental exposure for potential health effects. Also, sociodemographic characteristics have an influence on the exposure and therefore on the health effects for individuals. In future studies, this influence should be quantified and methods to assess the health impact should be improved.

Even though this review's focus was not on exposure studies incorporating medical data, it should be mentioned that there is a trend to combine environmental personal data with biomonitoring sensors in order to track individuals' health parameters, such as blood pressure, stress levels, or heart rate [80]. In addition to medical data, it can also be interesting for future studies to collect data of emotional perception to urban space [12, 64, 97, 112, 131], e.g., parameters of subjective perception of environmental pollution, and to investigate their relation to environmental parameters.

Based on these findings, we formulated five take-home messages for the reader:

1. Development of new sensors is absolutely necessary with regard to the trend towards multiple exposure studies and with respect to usability and human-computer interaction (HCI) aspects.

2. Personal exposure varies depending on different influencing factors (e.g., mode of transport, urban structure). The characterization of these factors concerning the extent of their influence and how they influence each other as well as the influence concerning the mode of transport should be further explored.

3. It would be desirable to carry out future studies in regions that have been underrepresented here (e.g., Africa, Asia), but are of particular interest due to high exposure levels as well as high population density.

4. Studies should investigate the association between exposure time and intensity and health effects of environmental exposure in different environments.

5. The rapidly advancing development of sensors will enable them to be widely used in the near future.

\section{Conclusions}

With this review, we give an overview of the growing number of case studies within the last 5 years applying mobile sensors (wearables) to measure environmental parameters in urban space. Such a review has been missing so far. We did a literature review and analyzed the characteristics (study design, parameters, and equipment) of 55 case studies as well as synthesized their limitations and results. Our study shows that there is a growing number of studies that use wearables to measure multiple parameters and thus contribute to research of the human exposome. There is a need to develop new sensors that can simultaneously record multiple parameters and are easy to use. Since there are many 
factors that influence the measurement data, it is necessary to identify and quantify them in order to avoid biased results in future studies.

Supplementary Information The online version contains supplementary material available at https://doi.org/10.1007/s40726-021-00186-4.

Author Contribution All authors contributed to the design and implementation of the research, to the analysis of the results, and to the writing of the manuscript.

Funding Open Access funding enabled and organized by Projekt DEAL. The research was supported by the funding from DGF in VGI Science program (contract number SCHL521/8-1).

Availability of Data and Material The reviewed papers are available on the website of the respective publishers.

Code Availability Not applicable

\section{Compliance with Ethical Standards}

Conflict of Interest There are no conflicts of interest.

Human and Animal Rights and Informed Consent This article does not contain any studies with human or animal subjects performed by any of the authors.

Open Access This article is licensed under a Creative Commons Attribution 4.0 International License, which permits use, sharing, adaptation, distribution and reproduction in any medium or format, as long as you give appropriate credit to the original author(s) and the source, provide a link to the Creative Commons licence, and indicate if changes were made. The images or other third party material in this article are included in the article's Creative Commons licence, unless indicated otherwise in a credit line to the material. If material is not included in the article's Creative Commons licence and your intended use is not permitted by statutory regulation or exceeds the permitted use, you will need to obtain permission directly from the copyright holder. To view a copy of this licence, visit http://creativecommons.org/licenses/by/4.0/.

\section{References}

1. Abhijith KV, Kumar P, Gallagher J, McNabola A, Baldauf R, Pilla F, et al. Air pollution abatement performances of green infrastructure in open road and built-up street canyon environments - a review. Atmos Environ. 2017;162:71-86. https://doi.org/10. 1016/j.atmosenv.2017.05.014

2. Aletta F, Van Renterghem T, Botteldooren D. Influence of personal factors on sound perception and overall experience in urban green areas. A case study of a cycling path highly exposed to road traffic noise. Int J Environ Res Public Health. 2018;15(6):1-17. https://doi.org/10.3390/ijerph15061118.

3. Andrianou XD, Makris KC. The framework of urban exposome: application of the exposome concept in urban health studies. Sci
Total Environ. 2018;636:963-7. https://doi.org/10.1016/j. scitotenv.2018.04.329.

4. Arbuthnott KG, Hajat S. The health effects of hotter summers and heat waves in the population of the United Kingdom: a review of the evidence. Environmental Health : a global access science source. 2017;16(1):1-13. https://doi.org/10.1186/s12940-0170322-5.

5. Aspuru I, García I, Herranz K, Santander A. CITI-SENSE: methods and tools for empowering citizens to observe acoustic comfort in outdoor public spaces. 2016;3(1). https://doi.org/10. 1515/noise-2016-0003.

6. Aumond P, Can A, Mallet V, De Coensel B, Ribeiro C, Botteldooren D, et al. Kriging-based spatial interpolation from measurements for sound level mapping in urban areas. J Acoust Soc Am. 2018;143(5):2847. https://doi.org/10.1121/1.5034799.

7. Babisch W. Updated exposure-response relationship between road traffic noise and coronary heart diseases: a meta-analysis. Noise \& health. 2014;16(68):1-9. https://doi.org/10.4103/1463-1741. 127847.

8. Bailey E, Fuhrmann C, Runkle J, Stevens S, Brown M, Sugg M. Wearable sensors for personal temperature exposure assessments: a comparative study. Environ Res. 2020;180:108858. https://doi. org/10.1016/j.envres.2019.108858.

9. Bakogiannis E, Kyriakidis C, Siti M, Kougioumtzidis N, Potsiou C. The use of Volunteered Geographic Information (VGI) in noise mapping. GeoPreVi 2017 - Article of the Month FIG (February 2018)2018.

10. Bekö G, Kjeldsen BU, Olsen Y, Schipperijn J, Wierzbicka A, Karottki DG, et al. Contribution of various microenvironments to the daily personal exposure to ultrafine particles: personal monitoring coupled with GPS tracking. Atmos Environ. 2015;110: 122-9. https://doi.org/10.1016/j.atmosenv.2015.03.053.

11. Bernhard MC, Kent ST, Sloan ME, Evans MB, McClure LA, Gohlke JM. Measuring personal heat exposure in an urban and rural environment. Environ Res. 2015a;137:410-8. https://doi. org/10.1016/j.envres.2014.11.002.

12. Birenboim A, Dijst M, Scheepers FE, Poelman MP, Helbich M. Wearables and location tracking technologies for mental-state sensing in outdoor environments. Prof Geogr. 2019;71(3):449 61. https://doi.org/10.1080/00330124.2018.1547978.

13. Borrego C, Costa AM, Ginja J, Amorim M, Coutinho M, Karatzas $\mathrm{K}$, et al. Assessment of air quality microsensors versus reference methods: the EuNetAir joint exercise. Atmos Environ. 2016;147: 246-63. https://doi.org/10.1016/j.atmosenv.2016.09.050.

14. Brum-Bastos VS, Long JA, Demsar U. Weather effects on human mobility: a study using multi-channel sequence analysis. Comput Environ Urban Syst. 2018;71:131-52. https://doi.org/10.1016/j. compenvurbsys.2018.05.004.

15. Budde M, Riedel T, Beigl M, Schäfer K, Emeis S, Cyrys J et al., editors. SmartAQnet: remote and in-situ sensing of urban air quality. SPIE Remote Sens 2017a: SPIE.

16. Budde M, Schankin A, Hoffmann J, Danz M, Riedel T, Beigl M. Participatory sensing or participatory nonsense? Proceedings of the ACM on Interactive, Mobile. Wearable Ubiquitous Technol. 2017b;1(3):1-23. https://doi.org/10.1145/3131900.

17. Bunz M, Wothge J. Fachliche Einschätzung der Lärmwirkungsstudie NORAH. Dessau: Umweltbundesamt 2016.

18. Cao T, Thompson JE. Personal monitoring of ozone exposure: a fully portable device for under \$150 USD cost. Sensors Actuators B Chem. 2016;224:936-43. https://doi.org/10.1016/j.snb.2015. 10.090 .

19. Cao X, Wang DG. Environmental correlates of residential satisfaction: an exploration of mismatched neighborhood characteristics in the Twin Cities. Landsc Urban Plan. 2016;150:26-35. https://doi.org/10.1016/j.landurbplan.2016.02.007. 
20. Cartenì A, Cascetta F, Campana S. Underground and ground-level particulate matter concentrations in an Italian metro system. Atmos Environ. 2015;101:328-37. https://doi.org/10.1016/j. atmosenv.2014.11.030.

21. Castell N, Dauge FR, Schneider P, Vogt M, Lerner U, Fishbain B, et al. Can commercial low-cost sensor platforms contribute to air quality monitoring and exposure estimates? Environ Int. 2017;99: 293-302. https://doi.org/10.1016/j.envint.2016.12.007.

22. Chaix B. Mobile sensing in environmental health and neighborhood research. Annu Rev Public Health. 2018;39:367-84. https:// doi.org/10.1146/annurev-publhealth-040617-013731.

23. Chatzidiakou L, Krause A, Popoola OAM, Di Antonio A, Kellaway M, Han Y, et al. Characterising low-cost sensors in highly portable platforms to quantify personal exposure in diverse environments. Atmos MeasurTech. 2019;12(8):4643-57. https:// doi.org/10.5194/amt-12-4643-2019.

24. Cole-Hunter T, Morawska L, Stewart I, Jayaratne R, Solomon C. Inhaled particle counts on bicycle commute routes of low and high proximity to motorised traffic. Atmos Environ. 2012;61:197-203. https://doi.org/10.1016/j.atmosenv.2012.06.041.

25. Cole-Hunter T, Jayaratne R, Stewart I, Hadaway M, Morawska L, Solomon C. Utility of an alternative bicycle commute route of lower proximity to motorised traffic in decreasing exposure to ultra-fine particles, respiratory symptoms and airway inflammation-a structured exposure experiment. Environ Health. 2013;12(1):29. https://doi.org/10.1186/1476-069X-12-29.

26. Cole-Hunter T, Morawska L, Solomon C. Bicycle commuting and exposure to air pollution: a questionnaire-based investigation of perceptions, symptoms, and risk management strategies. J Phys Act Health. 2015;12(4):490-9. https://doi.org/10.1123/jpah.20130122.

27. Connors JP, Lei S, Kelly M. Citizen science in the age of neogeography: utilizing volunteered geographic information for environmental monitoring. Ann Assoc Am Geogr. 2012;102(6): 1267-89. https://doi.org/10.1080/00045608.2011.627058.

28. Crandall CG, Wilson TE. Human cardiovascular responses to passive heat stress. Compr Physiol. 2015;5(1):17-43. https://doi.org/ 10.1002/cphy.c140015.

29. de Coensel B, Sun K, Wei W. Dynamic noise mapping based on fixed and mobile sound measurements. EURONOISE 2015, Jun 2015, MAASTRICHT, France 2015. p. 6p.

30. de Nazelle A, Seto E, Donaire-Gonzalez D, Mendez M, Matamala $\mathrm{J}$, Nieuwenhuijsen MJ, et al. Improving estimates of air pollution exposure through ubiquitous sensing technologies. Environ Pollut. 2013;176:92-9. https://doi.org/10.1016/j.envpol.2012.12. 032.

31. Directive (EU) 2008/50/EG des Europäischen Parlaments und des Rates vom 21. Mai 2008 über Luftqualität und saubere Luft für Europa, ABl 2008 L 154/1-44.

32. Do Vale ID, Vasconcelos AS, Duarte GO. Inhalation of particulate matter in three different routes for the same OD pair: a case study with pedestrians in the city of Lisbon. J Transp Health. 2015;2(4): 474-82. https://doi.org/10.1016/j.jth.2015.07.003.

33. Dons E, Int Panis L, Van Poppel M, Theunis J, Wets G. Personal exposure to black carbon in transport microenvironments. Atmos Environ. 2012;55:392-8. https://doi.org/10.1016/j.atmosenv. 2012.03.020.

34. Dons E, Gotschi T, Nieuwenhuijsen M, de Nazelle A, Anaya E, Avila-Palencia I, et al. Physical Activity through Sustainable Transport Approaches (PASTA): protocol for a multi-centre, longitudinal study. BMC Public Health. 2015;15:1126. https://doi. org/10.1186/s12889-015-2453-3.

35. Dons E, Laeremans M, Orjuela JP, Avila-Palencia I, CarrascoTurigas G, Cole-Hunter T, et al. Wearable sensors for personal monitoring and estimation of inhaled traffic-related air pollution: evaluation of methods. Environ Sci Technol. 2017;51(3):1859 67. https://doi.org/10.1021/acs.est.6b05782.

36. Dumas JS, Jagger MA, Kintziger KW. Where to wear iButtons: individual level temperature and humidity observations for public health surveillance. American Meteorological Society, 96th Annual Meeting. https://ams.confex.com/ams/96Annual/ webprogram/Paper280434.html 2016.

37. European Comission. Air Quality Standards. 2021. https:// ec.europa.eu/environment/air/quality/standards.htm. Accessed 07.01.2021 2021.

38. Ferster C, Nelson T, Laberee K, Vanlaar W, Winters M. Promoting crowdsourcing for urban research: cycling safety citizen science in four cities. Urban Sci. 2017;1(2):21. https://doi.org/ 10.3390/urbansci1020021.

39. Fishbain B, Lerner U, Castell N, Cole-Hunter T, Popoola O, Broday DM, et al. An evaluation tool kit of air quality microsensing units. Sci Total Environ. 2017;575:639-48. https://doi. org/10.1016/j.scitotenv.2016.09.061.

40. Fuller S, Bulkeley $\mathrm{H}$. Changing countries, changing climates: achieving thermal comfort through adaptation in everyday activities. Area. 2013;45(1):63-9. https://doi.org/10.1111/j.1475-4762. 2012.01105.x.

41. Gaskins AJ, Hart JE. The use of personal and indoor air pollution monitors in reproductive epidemiology studies. Paediatr Perinat Epidemiol. 2019. https://doi.org/10.1111/ppe.12599.

42. Goldbach A, Kuttler W. Quantification of turbulent heat fluxes for adaptation strategies within urban planning. Int J Climatol. 2013;33(1):143-59. https://doi.org/10.1002/joc.3437.

43. Good N, Molter A, Ackerson C, Bachand A, Carpenter T, Clark ML, et al. The Fort Collins Commuter Study: impact of route type and transport mode on personal exposure to multiple air pollutants. J Expo Sci Environ Epidemiol. 2016;26(4):397-404. https:// doi.org/10.1038/jes.2015.68.

44. Goodchild MF. Citizens as sensors: the world of volunteered geography. GeoJournal. 2007;69(4):211-21. https://doi.org/10. 1007/s10708-007-9111-y.

45. Großmann K, Franck U, Heyde M, Schlink U, Schwarz N, Stark K. Sozial-räumliche Aspekte der Anpassung an Hitze in Städten. In: Marx A, editor. Klimaanpassung in Forschung und Politik. Wiesbaden: Springer; 2017.

46. Guillaume C, Petit G, Fortin N, Palominos G, et al. Noise mapping based on participative measurements. Noise Map. 2016;3(1):140 56.

47. Guo Y, Gasparrini A, Armstrong B, Li S, Tawatsupa B, Tobias A, et al. Global variation in the effects of ambient temperature on mortality: a systematic evaluation. Epidemiology. 2014;25(6): 781-9. https://doi.org/10.1097/EDE.0000000000000165.

48. Guo Y, Liu F, Lu Y, Mao Z, Lu H, Wu Y, et al. Factors affecting parent's perception on air quality-from the individual to the community level. Int J Environ Res Public Health. 2016;13(493):114. https://doi.org/10.3390/ijerph13050493.

49. Guo Y, Gasparrini A, Armstrong BG, Tawatsupa B, Tobias A, Lavigne E, et al. Heat wave and mortality: a multicountry, multicommunity study. Environ Health Perspect. 2017;125(8): 087006. https://doi.org/10.1289/EHP1026.

50. Haddad H, de Nazelle A. The role of personal air pollution sensors and smartphone technology in changing travel behaviour. J Transp Health. 2018;11:230-43. https://doi.org/10.1016/j.jth. 2018.08.001.

51. Han Y, Chen W, Chatzidiakou L, Yan L, Zhang H, Chan Q, et al. Effects of AIR pollution on cardiopuLmonary disEaSe in urban and peri-urban reSidents in Beijing: protocol for the AIRLESS study. Atmos Chem Phys. 2020. https://doi.org/10.5194/acp2020-208.

52. Hass AL, Ellis KN. Using wearable sensors to assess how a heatwave affects individual heat exposure, perceptions, and 
adaption methods. Int J Biometeorol. 2019;63(12):1585-95. https://doi.org/10.1007/s00484-019-01770-6.

53. Hu M, Che W, Zhang Q, Luo Q, Lin H. A multi-stage method for connecting participatory sensing and noise simulations. Sensors. 2015;15(2):2265-82. https://doi.org/10.3390/s150202265.

54. Hunecke M. Mobilitätsverhalten verstehen und verändern. Wiesbaden: Springer VS; 2015.

55. Jereb B, Batkovič T, Herman L, Šipek G, Kovše Š, Gregorič A, et al. Exposure to black carbon during bicycle commutingalternative route selection. Atmosphere. 2018;9(21):1-12. https://doi.org/10.3390/atmos9010021.

56. Jerrett M, Donaire-Gonzalez D, Popoola O, Jones R, Cohen RC, Almanza E, et al. Validating novel air pollution sensors to improve exposure estimates for epidemiological analyses and citizen science. Environ Res. 2017;158:286-94. https://doi.org/10.1016/j. envres.2017.04.023.

57. Kestens Y, Thierry B, Shareck M, Steinmetz-Wood M, Chaix B. Integrating activity spaces in health research: comparing the VERITAS activity space questionnaire with 7-day GPS tracking and prompted recall. Spat Spatiotemporal Epidemiol. 2018;25:19. https://doi.org/10.1016/j.sste.2017.12.003.

58. Kraas F, Leggewie C, Lemke P, Matthies E, Messner D, Nakicenovic N et al. WBGU: Der Umzug der Menschheit: Die transformative Kraft der Städte. Berlin 2016.

59. Kraus U, Breitner S, Hampel R, Wolf K, Cyrys J, Geruschkat U, et al. Individual daytime noise exposure in different microenvironments. Environ Res. 2015;140:479-87. https://doi.org/10.1016/j. envres.2015.05.006.

60. Krefis A, Augustin M, Schlünzen K, Oßenbrügge J, Augustin J. How does the urban environment affect health and well-being? A systematic review. Urban Sci. 2018;2(21):1-21. https://doi.org/ 10.3390/urbansci2010021

61. Kühling W Mehrfachbelastungen durch verschiedenartige Umwelteinwirkungen. In: Bolte G, Bunge C, Hornberg C, Köckler H, Mielck A, editors. Umweltgerechtigkeit. Huber; 2012.

62. Kuras ER, Hondula DM, Brown-Saracino J. Heterogeneity in individually experienced temperatures (IETs) within an urban neighborhood: insights from a new approach to measuring heat exposure. Int J Biometeorol. 2015a;59(10):1363-72. https://doi. org/10.1007/s00484-014-0946-X.

63. Kuras ER, Richardson MB, Calkins MM, Ebi KL, Hess JJ, Kintziger KW, et al. Opportunities and challenges for personal heat exposure research. Environ Health Perspect. 2017;125(8): 085001. https://doi.org/10.1289/EHP556.

64. Kyriakou K, Resch B, Sagl G, Petutschnig A, Werner C, Niederseer D, et al. Detecting moments of stress from measurements of wearable physiological sensors. Sensors (Basel). 2019;19(17):3805. https://doi.org/10.3390/s19173805.

65. Landrigan PJ, Fuller R, Acosta NJR, Adeyi O, Arnold R, Basu N, et al. The Lancet Commission on pollution and health. Lancet. 2017;391:462-512. https://doi.org/10.1016/s0140-6736(17) 32345-0.

66. Leaffer D, Wolfe C, Doroff S, Gute D, Wang G, Ryan P. Wearable ultrafine particle and noise monitoring sensors jointly measure personal co-exposures in a pediatric population. Int $\mathrm{J}$ Environ Res Public Health. 2019;16(3):14. https://doi.org/10. 3390/ijerph16030308.

67. Lefevre B, Issarny V. Matching technological \& societal innovations: the social design of a mobile collaborative app for urban noise monitoring. 2018. doi:https://doi.org/10.1109/smartcomp. 2018.00071 .

68. Lefevre B, Agarwal R, Issarny V, Mallet V. Mobile crowdsensing as a resource for contextualized urban public policies: a study using three use cases on noise and soundscape monitoring. Cities \& Health. 2019:1-19. https://doi.org/10.1080/23748834. 2019.1617656.
69. Lei X, Xiu G, Li B, Zhang K, Zhao M. Individual exposure of graduate students to PM2.5 and black carbon in Shanghai, China. Environ Sci Pollut Res Int. 2016;23(12):12120-7. https://doi.org/ 10.1007/s11356-016-6422-x.

70. Lelieveld J, Klingmuller K, Pozzer A, Poschl U, Fnais M, Daiber A et al. Cardiovascular disease burden from ambient air pollution in Europe reassessed using novel hazard ratio functions. Eur Heart J. 2019:1-7. doi:https://oi.org/10.1093/eurheartj/ehz135.

71. Leser H, Haas H-D, Meier S, Mosimann T, Paesler R. Wörterbuch Allgemeine Geographie. München: dtv; 2005.

72. Li B, Lei XN, Xiu GL, Gao CY, Gao S, Qian NS. Personal exposure to black carbon during commuting in peak and off-peak hours in Shanghai. Sci Total Environ. 2015;524-525:237-45. https://doi. org/10.1016/j.scitotenv.2015.03.088.

73. Lim S, Dirks KN, Salmond JA, Xie S. Determinants of spikes in ultrafine particle concentration whilst commuting by bus. Atmos Environ. 2015;112:1-8. https://doi.org/10.1016/j.atmosenv.2015. 04.025 .

74. Liu WT, Ma CM, Liu IJ, Han BC, Chuang HC, Chuang KJ. Effects of commuting mode on air pollution exposure and cardiovascular health among young adults in Taipei, Taiwan. Int J Hyg Environ Health. 2015;218(3):319-23. https://doi.org/10.1016/j. ijheh.2015.01.003.

75. Longo A, Zappatore M, Bochicchio M, Navathe SB. Crowdsourced data collection for urban monitoring via mobile sensors. ACM Trans Internet Technol. 2017;18(1):1-21. https://doi.org/ 10.1145/3093895.

76. Loreto V, Haklay M, Hotho A, Servedio VDP, Stumme G, Theunis J et al. Participatory sensing, opinions and collective awareness. Springer; 2017.

77. Louwies T, Nawrot T, Cox B, Dons E, Penders J, Provost E, et al. Blood pressure changes in association with black carbon exposure in a panel of healthy adults are independent of retinal microcirculation. Environ Int. 2015;75:81-6. https://doi.org/10.1016/j. envint.2014.11.006.

78. Lu Y, Fang T. Examining personal air pollution exposure, intake, and health danger zone using time geography and 3D geovisualization. ISPRS Int J Geo Inf. 2014;4(1):32-46. https:// doi.org/10.3390/ijgi4010032.

79. Ma J, Tao Y, Kwan M-P, Chai Y. Assessing mobility-based realtime air pollution exposure in space and time using smart sensors and GPS trajectories in Beijing. Ann Am Assoc Geogr. 2019:115. https://doi.org/10.1080/24694452.2019.1653752.

80. Majumder S, Aghayi E, Noferesti M, Memarzadeh-Tehran H, Mondal T, Pang Z, et al. Smart homes for elderly healthcarerecent advances and research challenges. Sensors. 2017;17(11): 2496. https://doi.org/10.3390/s17112496.

81. Mallires KR, Wang D, Tipparaju VV, Tao N. Developing a lowcost wearable personal exposure monitor for studying respiratory diseases using metal-oxide sensors. IEEE Sensors J. 2019;19(18): 8252-61. https://doi.org/10.1109/jsen.2019.2917435.

82. Marques G, Pitarma R. Noise mapping through mobile crowdsourcing for enhanced living environments. Comp Sci ICCS 2019:Lecture Notes in Computer Science. 2019;2019: 670-9.

83. Mazaheri M, Clifford S, Yeganeh B, Viana M, Rizza V, Flament $\mathrm{R}$, et al. Investigations into factors affecting personal exposure to particles in urban microenvironments using low-cost sensors. Environ Int. 2018;120:496-504. https://doi.org/10.1016/j.envint. 2018.08.033.

84. McKercher GR, Vanos JK. Low-cost mobile air pollution monitoring in urban environments: a pilot study in Lubbock. Texas Environ Technol. 2018;39(12):1505-14. https://doi.org/10.1080/ 09593330.2017 .1332106 .

85. Meier F, Fenner D, Grassmann T, Otto M, Scherer D. Crowdsourcing air temperature from citizen weather stations for 
urban climate research. Urban Clim. 2017;19:170-91. https://oi. org/10.1016/j.uclim.2017.01.006.

86. Monrad M, Sajadieh A, Christensen JS, Ketzel M, RaaschouNielsen O, Tjonneland A, et al. Long-term exposure to trafficrelated air pollution and risk of incident atrial fibrillation: a cohort study. Environ Health Perspect. 2017;125(3):422-7. https://doi. org/10.1289/EHP392.

87. Moore E, Chatzidiakou L, Jones RL, Smeeth L, Beevers S, Kelly FJ, et al. Linking e-health records, patient-reported symptoms and environmental exposure data to characterise and model COPD exacerbations: protocol for the COPE study. BMJ Open. 2016;6(7):e011330. https://doi.org/10.1136/bmjopen-2016011330 .

88. Morales Betancourt R, Galvis B, Balachandran S, Ramos-Bonilla JP, Sarmiento OL, Gallo-Murcia SM, et al. Exposure to fine particulate, black carbon, and particle number concentration in transportation microenvironments. Atmos Environ. 2017;157:135-45. https://doi.org/10.1016/j.atmosenv.2017.03.006.

89. Morawska L, Thai PK, Liu X, Asumadu-Sakyi A, Ayoko G, Bartonova A, et al. Applications of low-cost sensing technologies for air quality monitoring and exposure assessment: how far have they gone? Environ Int. 2018;116:286-99. https://doi.org/10. 1016/j.envint.2018.04.018.

90. Munzel T, Gori T, Babisch W, Basner M. Cardiovascular effects of environmental noise exposure. Eur Heart J. 2014;35(13):829 36. https://doi.org/10.1093/eurheartj/ehu030.

91. Nagendra SMS, Yasa PR, Narayana MV, Khadirnaikar S, Rani P. Mobile monitoring of air pollution using low cost sensors to visualize spatio-temporal variation of pollutants at urban hotspots. Sustain Cities Soc. 2019;44:520-35. https://doi.org/10.1016/j. scs.2018.10.006.

92. Nakayoshi M, Kanda M, Shi R, de Dear R. Outdoor thermal physiology along human pathways: a study using a wearable measurement system. Int J Biometeorol. 2015;59(5):503-15. https:// doi.org/10.1007/s00484-014-0864-y.

93. Nieuwenhuijsen MJ, Khreis H. Car free cities: pathway to healthy urban living. Environ Int. 2016;94:251-62. https://doi.org/10. 1016/j.envint.2016.05.032.

94. Nieuwenhuijsen $\mathrm{M}, \mathrm{Khreis} \mathrm{H}$. Integrating human health into urban and transport planning. Cham: Springer; 2018.

95. Nieuwenhuijsen MJ, Donaire-Gonzalez D, Rivas I, de Castro M, Cirach M, Hoek G, et al. Variability in and agreement between modeled and personal continuously measured black carbon levels using novel smartphone and sensor technologies. Environ Sci Technol. 2015;49(5):2977-82. https://doi.org/10.1021/ es505362x.

96. Okokon EO, Yli-Tuomi T, Turunen AW, Taimisto P, Pennanen A, Vouitsis I, et al. Particulates and noise exposure during bicycle, bus and car commuting: a study in three European cities. Environ Res. 2017;154:181-9. https://doi.org/10.1016/j.envres.2016.12. 012.

97. Osborne T, Jones PI. Biosensing and geography: a mixed methods approach. Appl Geogr. 2017;87:160-9. https://doi.org/10.1016/j. apgeog.2017.08.006.

98. Perchoux C, Chaix B, Brondeel R, Kestens Y. Residential buffer, perceived neighborhood, and individual activity space: new refinements in the definition of exposure areas - The RECORD Cohort Study. Health Place. 2016;40:116-22. https://doi.org/10. 1016/j.healthplace.2016.05.004.

99. Picaut J, Fortin N, Bocher E, Petit G, Aumond P, Guillaume G. An open-science crowdsourcing approach for producing community noise maps using smartphones. Build Environ. 2019;148:20-33. https://doi.org/10.1016/j.buildenv.2018.10.049.

100. Ramírez O, Mura I, Franco JF. How do people understand urban air pollution? Exploring citizens' perception on air quality, its causes and impacts in Colombian cities. Open J Air Pollut. 2017;6(1):1-17. https://doi.org/10.4236/ojap.2017.61001.

101. Rana R, Chou CT, Bulusu N, Kanhere S, Hu W. Ear-Phone: a context-aware noise mapping using smart phones. Pervasive Mobile Comp. 2015;17:1-22. https://doi.org/10.1016/j.pmcj. 2014.02.001.

102. Recio A, Linares C, Banegas JR, Diaz J. The short-term association of road traffic noise with cardiovascular, respiratory, and diabetes-related mortality. Environ Res. 2016;150:383-90. https://doi.org/10.1016/j.envres.2016.06.014.

103. Richardson DB. Real-time space-time integration in GIScience and Geography. Ann Assoc Am Geogr. 2013;103(5):1062-71. https://doi.org/10.1080/00045608.2013.792172.

104. Rivas I, Donaire-Gonzalez D, Bouso L, Esnaola M, Pandolfi M, de Castro M, et al. Spatiotemporally resolved black carbon concentration, schoolchildren's exposure and dose in Barcelona. Indoor Air. 2016;26(3):391-402. https://doi.org/10.1111/ina. 12214.

105. Rivas I, Kumar P, Hagen-Zanker A. Exposure to air pollutants during commuting in London: are there inequalities among different socio-economic groups? Environ Int. 2017;101:143-57. https://doi.org/10.1016/j.envint.2017.01.019.

106. Runkle J, Sugg M, Boase D, Galvin SL, Coulson CC. Use of wearable sensors for pregnancy health and environmental monitoring: descriptive findings from the perspective of patients and providers. Digit Health. 2019a;5:2055207619828220. https://doi. org/10.1177/2055207619828220.

107. Runkle JD, Cui C, Fuhrmann C, Stevens S, Del Pinal J, Sugg MM. Evaluation of wearable sensors for physiologic monitoring of individually experienced temperatures in outdoor workers in southeastern U.S. Environ Int. 2019b;129:229-38. https://doi.org/10. 1016/j.envint.2019.05.026.

108. Ryan PH, Son SY, Wolfe C, Lockey J, Brokamp C, LeMasters G. A field application of a personal sensor for ultrafine particle exposure in children. Sci Total Environ. 2015a;508:366-73. https://doi. org/10.1016/j.scitotenv.2014.11.061.

109. Salomon M, Brodner B, Hornberg C. Umweltbezogener Gesundheitsschutz im städtischen Lebensraum. Public Health Forum. 2018;26(3):247-51. https://doi.org/10.1515/pubhef2018-0078.

110. Schlink U, Ueberham M. Perspectives of individual-worn sensors assessing personal environmental exposure. Engineering (Beijing). 2020. https://doi.org/10.1016/j.eng.2020.07.023.

111. Schraufnagel DE. The health effects of ultrafine particles. Exp Mol Med. 2020;52(3):311-7. https://doi.org/10.1038/s12276020-0403-3.

112. Shoval N, Schvimer Y, Tamir M. Tracking technologies and urban analysis: adding the emotional dimension. Cities. 2018;72: 34-42. https://doi.org/10.1016/j.cities.2017.08.005.

113. So R, Jørgensen J, Hertel O, Brunekreef B, Hoek G, Sigsgaard T, et al. Long-term exposure to PM2.5 and road traffic noise and allcause natural mortality: a Danish Nurse Cohort Study. Environ Epidemiol. 2019;3:375-6.

114. Spinazzè A, Cattaneo A, Scocca DR, Bonzini M, Cavallo DM Multi-metric measurement of personal exposure to ultrafine particles in selected urban microenvironments. Atmos Environ. 2015;110:8-17. https://doi.org/10.1016/j.atmosenv.2015.03.034.

115. Steinle S, Reis S, Sabel CE, Semple S, Twigg MM, Braban CF, et al. Personal exposure monitoring of PM2.5 in indoor and outdoor microenvironments. Sci Total Environ. 2015;508:383-94. https://doi.org/10.1016/j.scitotenv.2014.12.003.

116. Strak M, Janssen N, Beelen R, Schmitz O, Vaartjes I, Karssenberg $\mathrm{D}$, et al. Long-term exposure to particulate matter, $\mathrm{NO} 2$ and the oxidative potential of particulates and diabetes prevalence in a large national health survey. Environ Int. 2017;108:228-36. https://doi.org/10.1016/j.envint.2017.08.017. 
117. Sugg MM, Fuhrmann CM, Runkle JD. Temporal and spatial variation in personal ambient temperatures for outdoor working populations in the southeastern USA. Int J Biometeorol. 2018;62(8): 1521-34. https://doi.org/10.1007/s00484-018-1553-z.

118. Targino AC, Rodrigues MVC, Krecl P, Cipoli YA, Ribeiro JPM. Commuter exposure to black carbon particles on diesel buses, on bicycles and on foot: a case study in a Brazilian city. Environ Sci Pollut Res Int. 2018;25(2):1132-46. https://doi.org/10.1007/ s11356-017-0517-x.

119. Thompson L, Sugg M, Runkle J. Report-back for geo-referenced environmental data: a case study on personal monitoring of temperature in outdoor workers. Geospat Health. 2018;13(1):629. https://doi.org/10.4081/gh.2018.629.

120. Ueberham M, Schlink U. Wearable sensors for multifactorial personal exposure measurements - a ranking study. Environ Int. 2018;121(1):130-8. https://doi.org/10.1016/j.envint.2018.08.057.

121. Ueberham M, Schlink U, Dijst M, Weiland U. Cyclists' multiple environmental urban exposures - comparing subjective and objective measurements. Sustainability-Basel. 2019;11(5):1412. https://doi.org/10.3390/su11051412.

122. Uejio CK, Morano LH, Jung J, Kintziger K, Jagger M, Chalmers $\mathrm{J}$, et al. Occupational heat exposure among municipal workers. Int Arch Occup Environ Health. 2018;91(6):705-15. https://doi.org/ 10.1007/s00420-018-1318-3.

123. van Kempen E, Babisch W. The quantitative relationship between road traffic noise and hypertension: a meta-analysis. J Hypertens. 2012;30(6):1075-86. https://doi.org/10.1097/HJH. 0b013e328352ac54.

124. Ventura R, Mallet V, Issarny V. Assimilation of mobile phone measurements for noise mapping of a neighborhood. J Acoust Soc Am. 2018;144(3):1279. https://doi.org/10.1121/1.5052173.

125. Verbeek T. The relation between objective and subjective exposure to traffic noise around two suburban highway viaducts in
Ghent: lessons for urban environmental policy. Local Environ. 2018;23(4):448-67. https://doi.org/10.1080/13549839.2018. 1428791 .

126. von Szombathely M, Albrecht M, Augustin J, Bechtel B, Dwinger I, Gaffron P, et al. Relation between observed and perceived traffic noise and socio-economic status in urban blocks of different characteristics. Urban Sci. 2018;2:20. https://doi.org/10.3390/ urbansci2010020.

127. WHO WHO. Environmental Noise Guideline for the European Region. Copenhagen 2018.

128. Williams RD, Knibbs LD. Daily personal exposure to black carbon: a pilot study. Atmos Environ. 2016;132:296-9. https://doi. org/10.1016/j.atmosenv.2016.03.023.

129. Wu X, Braun D, Schwartz J, Kioumourtzoglou MA, Dominici F. Evaluating the impact of long-term exposure to fine particulate matter on mortality among the elderly. Sci Adv. 2020;6(29): eaba5692. https://doi.org/10.1126/sciadv.aba5692.

130. Yatkin S, Gerboles M, Belis CA, Karagulian F, Lagler F, Barbiere $\mathrm{M}$, et al. Representativeness of an air quality monitoring station for PM2.5 and source apportionment over a small urban domain. Atmos Pollut Res. 2020;11(2):225-33. https://doi.org/10.1016/j. apr.2019.10.004.

131. Zeile P, Resch B, Exner J-P, Sagl G. Urban emotions: benefits and risks in using human sensory assessment for the extraction of contextual emotion information in urban planning. Planning Support Systems and Smart Cities. Lecture Notes in Geoinformation and Cartography, 2015. p. 209-25.

Publisher's Note Springer Nature remains neutral with regard to jurisdictional claims in published maps and institutional affiliations. 